\title{
Emergency Vagotomy and Pyloroplasty for Perforated Duodenal Ulcer: Study of 73 Cases
}

\author{
M. G. MACHAYYA,* M.B., F.R.C.S.
}

\begin{abstract}
Summary : Seventy-three unselected patients with perforated duodenal ulcer were treated by vagotomy and pyloroplasty in a six-year period. Postoperative complications were commoner when the operation was carried out after more than six hours after perforation. The follow-up results were similar to those for elective vagotomy and pyloroplasty carried out in the hospital during the past nine years.
\end{abstract}

\section{Introduction}

At the present time most patients suffering from perforated duodenal ulcer are treated surgically unless strong contraindications to operation lead to conservative treatment. Of the possible surgical methods of treatment of this emergency the simplest procedure is closure of the perforation to stop the "leak." This remains the most popular and commonly practised operation for perforated duodenal ulcer. However, as Shepherd (1968) points out, only $25 \%$ of patients so treated are likely to remain symptom-free. Most of the remaining $75 \%$ will have further surgery.

A more radical curative procedure at the time of dealing with the perforation would therefore seem indicated if it could be shown not to increase the mortality or morbidity. It is probable that partial gastrectomy in the presence of a perforation, even when performed by senior skilled staff, would increase morbidity and mortality. Vagotomy with a simple drainage procedure is currently in vogue as the elective operation in the surgical treatment of duodenal ulcer. The operative mortality seems acceptably low, but the recurrence rate is a little higher than after gastric resection. The operation is certainly technically easier and quicker than gastric resection, and this may be advantageous in the presence of duodenal perforation.

The purpose of this communication is to present the merits of vagotomy and pyloroplasty for perforated duodenal ulcer.

\section{Material and Method}

The patients in this series were admitted to the North Lonsdale Hospital during the past six years. The diagnosis of perforated duodenal ulcer was established by the clinical history of chronic indigestion and duodenal ulcer symptoms with severe abdominal pain of recent onset and a rigid silent abdomen. The clinical diagnosis was confirmed by a plain radiograph taken in the sitting position. In $60 \%$ of the patients in this series free gas was radiologically demonstrated within the peritoneal cavity.

Immediately the diagnosis was established gastric aspiration was begun with a nasogastric tube, and an intravenous infusion was set up to correct the water and electrolyte imbalance.

In these patients speed and gentleness are important, and for this reason a generous upper midline incision was preferred. Once the abdomen was opened the peritoneum was cleared of contaminants so far as possible. The pyloroduodenal region was then incised longitudinally. The incision extended $5 \mathrm{~cm}$. on each side of the pylorus and included the actual perforation. Through this pylorotomy the gastric content was aspirated and the pyloroplasty completed in the fashion described by Heineke and Mikulicz. By doing the pyloroplasty first a relatively clear field was left for the second part of the operation-namely, truncal vagotomy. Selective vagotomy was not done. Then the peritoneum over the oesophagus was incised and a soft rubber tube was passed round the gastro-oesophageal junction as a sling, to facilitate traction. With the oesophagus taut it was possible to identify the trunks of the anterior and posterior vagi. About $2 \mathrm{~cm}$. of each trunk was excised and the cut ends of the nerves were ligated. Following this, and after a final mop-up of the peritoneum, the abdomen was closed with monofilament nylon for the peritoneum and aponeurosis and mersilene sutures for the skin. A corrugated drain placed in the hepatorenal pouch through a stab incision was used in all cases of this series.

\section{Findings and Results}

The incidence of immediate postoperative complications at various ages and in relation to length of perforation-operation interval is shown in Table $\mathrm{I}$. Of the 73 patients treated, 52 were operated on within six hours of the onset of perforation symptoms and 21 after a longer interval. The incidence of postoperative complications was much lower in the group that came to surgery within six hours. Of these, $13(25 \%)$ developed postoperative complications: six had mild basa pneumonia, and seven had mild wound infection. These complications rapidly responded to antibiotics given for five to seven days. In the second group of 21 patients $10(47.6 \%)$ developed postoperative complications : one 48 -year-old patient developed a right posterior subphrenic abscess on the fifth postoperative day, and this required drainage. Of the three other patients who developed wound infection a 65-year-old later had a burst abdomen, which healed satisfactorily after resuture. One of these patients had basal pneumonia and one had pulmonary infarction due to embolus from deep vein thrombosis. Postoperative shock was noted in two patients-

TABLE I.-Immediate Postoperative Complications

\begin{tabular}{|c|c|c|c|c|c|c|}
\hline \multirow{2}{*}{ Group } & \multirow{2}{*}{$\begin{array}{l}\text { Total } \\
\text { No. }\end{array}$} & \multirow{2}{*}{$\begin{array}{c}\text { Age } \\
\text { Range } \\
\text { (Years) }\end{array}$} & \multicolumn{3}{|c|}{$\begin{array}{l}\text { No. with } \\
\text { Postoperative Complications }\end{array}$} & \multirow{2}{*}{$\begin{array}{c}\text { No. of } \\
\text { Deaths in } \\
\text { Immediate } \\
\text { Post } \\
\text { operative } \\
\text { Period }\end{array}$} \\
\hline & & & $\begin{array}{l}\text { Chest } \\
\text { Infection }\end{array}$ & $\begin{array}{l}\text { Wound } \\
\text { Infection }\end{array}$ & Others & \\
\hline $\begin{array}{c}\text { Patients } \\
\text { operated on } \\
\text { within } 6 \\
\text { hours after } \\
\text { perforation }\end{array}$ & $\begin{array}{r}14 \\
24 \\
12 \\
2\end{array}$ & $\begin{array}{c}20-40 \\
40-60 \\
60-75 \\
\text { Over } 75\end{array}$ & $\begin{array}{l}1 \\
3 \\
1 \\
1\end{array}$ & $\begin{array}{l}1 \\
5 \\
1 \\
-\end{array}$ & $=$ & 1 \\
\hline $\begin{array}{l}\text { Patients } \\
\text { operated } \\
\text { on at } \\
6 \text { hours } \\
\text { or more } \\
\text { after } \\
\text { purforation }\end{array}$ & $\begin{array}{l}3 \\
9\end{array}$ & $\begin{array}{l}20-40 \\
40-60\end{array}$ & $\begin{array}{l}-\overline{1} \\
\text { (also leg vein } \\
\text { thrombosis } \\
\text { and } \\
\text { pulmonary } \\
\text { infarction) } \\
1\end{array}$ & $\begin{array}{c}\begin{array}{c}1 \\
\text { (also burst } \\
\text { abdomen) }\end{array} \\
-\end{array}$ & \begin{tabular}{|c|}
1 \\
subphrenic \\
abscess. 1 \\
hypovolaemic \\
shock \\
1 \\
cardiogenic \\
shock. 1 \\
obstructive \\
jaundice \\
-
\end{tabular} & 1 \\
\hline
\end{tabular}


one aged 67 had myocardial infarction with cardiac failure, and the other, aged 42 , was dehydrated and responded to fluid replacement by intravenous infusion. One patient developed mild obstructive jaundice on the thirteenth postoperative day and was later found to have gallstones.

The majority of the patients-that is, those without complications-stayed in hospital for periods of 12 to 14 days. Three patients who stayed for longer periods were the cases of supphrenic abscess (26 days), pulmonary infarct (28 days), and wound infection with burst abdomen (30 days).

There were four deaths in the immediate postoperative period. The age, perforation-operation interval, and the cause of death are shown in Table II. The average age of three of these patients was 79 . The perforation-operation interval may well be inaccurate in these old people. The reason for the prolonged unconsciousness in the patient aged 50 was not ascertained, but it was thought to be connected with the anaesthetic.

TABLE II.-Deaths in Immediate Postoperative Period

\begin{tabular}{c|c|c}
\hline Age & $\begin{array}{c}\text { Perforation-Operation } \\
\text { Interval }\end{array}$ & \multicolumn{1}{c}{$\begin{array}{c}\text { Cause of } \\
\text { Death }\end{array}$} \\
\hline 78 & $\begin{array}{c}\text { 3-4 hours } \\
\text { More than 12 hours }\end{array}$ & $\begin{array}{l}\text { Peritonitis. Died 6th day } \\
\text { Died of anuria, uraemia, and irreversible } \\
\text { shock 3 hours later } \\
\text { Died in 8 hours with myocardial ischaemia } \\
\text { Died in 48 hours. Prolonged unconscious- } \\
\text { ness after anaesthetic }\end{array}$ \\
\hline
\end{tabular}

It was possible to assess the results of the operation by follow-up studies of the patients in this series at intervals between six months and five years. In addition to the routine follow-up at the clinic a special survey was conducted recently for assessment of long-term results of the operation. In this survey it came to light that eight of the patients included in the series have died during the follow-up period at intervals of six months to four years after the operation; however, the case records of these patients showed that they did not have recurrence of ulcer symptoms during the follow-up period, and the causes of death were unrelated to the gastric operation. Five other patients included in this series were not present at the recent survey, but their case records showed that they did attend the follow-up clinic until last year, and had been symptom-free for two to three years since the operation.

During the follow-up period and in the recent survey details of dyspepsia, discomfort, vomiting, bowel habits, variation in body weight, and the work record have been noted. The results were classified into four categories, the modified Visick classification as described by Goligher et al. (1968) being used. Among the patients in this series $30(41 \%)$ were in category 1 (excellent), $23(31.5 \%)$ in category 2 (very good), $10(13.5 \%)$ in category 3 (satisfactory), and $6(8 \%$ ) in category 4 (unsatisfactory). These proved similar to the results noted for elective vagotomy and pyloroplasty carried out in this hospital during the past nine years.

\section{Discussion}

Immediate surgical closure of the perforated duodenal ulcer is to many the procedure of choice. Conservative treatment of perforated duodenal ulcer, attractive in that it left surgery as an elective procedure for a later date, has not been widely adopted, as it seemed least efficient in bad-risk cases. Simple closure is applicable to most cases of perforated duodenal ulcer, but occasionally where there is pyloric stenosis a pyloroplasty or a bypass procedure is necessary. Pyloroplasty adds little to the time needed to deal with the perforation ; in some cases it makes closure of the perforation easier.

Theoretically the addition of vagotomy in the presence of a soiled abdomen might be expected to increase the incidence of complications. Vagotomy in itself seems to carry a small risk (a) of perforation of the oesophagus, rare unless in the presence of oesophagitis, or at a second operation in the region of the oesophagogastric junction; and $(b)$ mediastinitis; the incidence of this complication might be expected to increase in the presence of potentially if not actually infected material entering the mediastinum through the oesophageal hiatus. It is reasonable to attribute a high incidence of chest infection to the possible entry of organisms into the mediastinum through the oesophageal hiatus. For this reason no attempt was made to close the oesophageal hiatus after vagotomy. However, in all cases evidence of infection rapidly disappeared with antibiotic therapy. No late complications such as stricture of the lower oesophagus or hiatal herniation have come to light.

Insulin test meal was carried out for five of the six patients in category 4 of this series. Of these, two were proved to have incomplete vagotomy, and further exploration with vagotomy and antrectomy had to be carried out at a later stage. In two others the insulin test was negative, and radiological proof of recurrence of the ulcer was lacking. In one other patient the unsatisfactory result was due to chronic duodenal ileus, as was demonstrated by radiological examination. The insulin test meal was not carried out routinely in the remaining patients in this series.

If the more conservative approach is taken-that is, simple closure of perforation with elective surgery at a later datethen for comparative purposes the immediate morbidity and mortality of this operation together with a second operation in about $75 \%$ of cases should be compared with the morbidity and mortality of immediate vagotomy and pyloroplasty. By doing the elective procedure at the time of perforation a second operation is avoided in a substantial number of patients.

I am indebted to Mr. A. W. B. Strachan and Mr. H. A. Daniels, consultant surgeons, North Lonsdale Hospital, Barrow-in-Furness, for permission to study patients under their care and for their encouragement and help in preparing this paper; to Mrs. J. Cornthwaite and her staff for the secretarial help; and to the many patients included in this series without whose co-operation this study could not have been possible.

\section{REFERENCES}

Aird, I. (1958). Companion in Surgical Studies, 2nd ed., p. 737. Edin-

burgh.
Goligher, J. C., et al. (1968). Brit. med. F., 2, 781.

Hadfield, J. I. H., and Watkin, D. F. L. (1964). Brit. med. F., 2, 12.

Haubrich, W. S. (1963). Gastroenterology, by H. L. Bockus et al., 2nd ed., vol. 1, Chapt. 27. London.

Jordan, G. L., jun., Angel, R. T., and deBakey, M. E. (1966). Arch. Surg., 92, 449.

Macleod; I. B. (1967). F. roy. Coll. Surg. Edinb., 12, 285

Mann, C. V. (1967). f. roy. Coll. Surg. Edinb., 12, 285.

Mann, C. V. (1967). Hosp. Med., 1, 389.

Pierandozzi, J. S., Hinshaw D. B., and Stafford, C. E. (1960). Amer. F. Surg., 100, 245.

Shepherd, J. A. (1968). Brit. med. F., 1, 625.

Williams, J. A. (1968). Proc. roy. Soc. Med., 61, 211. 